\title{
DEVELOPMENT OF SOLID SELF-MICROEMULSIFYING DRUG DELIVERY SYSTEM OF DIACEREIN FOR ENHANCED DISSOLUTION RATE
}

\author{
JAMEER A TAMBOLI*, SHRINIVAS K MOHITE \\ Department of Pharmaceutics, Rajarambapu College of Pharmacy, Sangli, Maharashtra, India. Email: jamir2u@gmail.com
}

Received: 05 September 2018, Revised and Accepted: 29 October 2018

ABSTRACT

Objective: The objective of the present study was to develop solid self-microemulsifying drug delivery system (S-SMEDDS) of diacerein (DCN) for enhancement of dissolution rate.

Methods: Three batches of liquid SMEDDS were prepared using oleic acid, Tween 80, and polyethylene glycol 200 as oil, surfactant, and cosurfactant, respectively. Microemulsion region was recognized by constructing a pseudoternary phase diagram containing a different proportion of oil, surfactant, and cosurfactant. Prepared liquid SMEDDS was evaluated for thermodynamic stability study, dispersibility tests, globule size, zeta potential, and viscosity. Liquid SMEDDS was then converted to S-SMEDDS by adsorption technique using Neusilin US2 as a solid carrier. Prepared S-SMEDDS was evaluated for different micromeritic properties, drug content, reconstitution properties, in vitro dissolution study, Fourier transform infrared, and scanning electron microscopy.

Results: The results showed that all batches of liquid SMEDDS were found to be thermodynamically stable. Reconstitution properties of S-SMEDDS showed spontaneous microemulsification with globule size $0.271 \mu \mathrm{m}$ and $-16.18 \mathrm{mV}$ zeta potential. From the results of in vitro dissolution study, it was found that the release of DCN was significantly increased as compared with plain DCN.

Conclusion: The study concluded that dissolution rate of poorly water-soluble drug like DCN can be increased by developing S-SMEDDS formulation.

Keywords: Diacerein, In vitro dissolution study, Neusilin US2, Pseudoternary phase diagram, Self-microemulsifying drug delivery system.

(c) 2019 The Authors. Published by Innovare Academic Sciences Pvt Ltd. This is an open access article under the CC BY license (http://creativecommons. org/licenses/by/4. 0/) DOI: http://dx.doi.org/10.22159/ajpcr.2019.v12i2.29500

\section{INTRODUCTION}

Oral drug delivery is used for many years through different dosage forms due to its easy administration and good patient compliance [1]. It has been projected that about $70 \%$ of new chemical entities (NCE) entering drug development programs have poor water solubility to consign consistent gastrointestinal absorption in sufficient concentration to ensure therapeutic efficacy [2]. Various approaches have been used to improve solubility and dissolution rate of the poorly water-soluble drug. Among them, self-microemulsifying drug delivery systems (SMEDDSs) have shown great promise for enhancing bioavailability of poorly soluble compounds [3]. SMEDDSs are isotropic mixtures of drug, lipids, and surfactants, usually with one or more hydrophilic cosolvents or emulsifiers. On mild agitation followed by dilution with aqueous media, these systems can form fine (oil in water) emulsion instantaneously [4]. SMEDDSs are generally encapsulated either in hard or soft gelatin capsules. Lipid formulations, however, may interact with the capsule resulting in either brittleness or softness of the shell [5]. To overcome this problem, SMEDDSs need to convert into solid SMEDDS (S-SMEDDS). The major techniques for converting SMEDDS to S-SMEDDS are spray cooling, spray drying, adsorption onto solid carriers, melt granulation, melt extrusion, supercritical fluid-based methods, and high-pressure homogenization. However, the adsorption process is simple and involves simple addition of the liquid formulation to solid carriers by mixing in a blender [6]. Neusilin US2 is a fine ultra-light granule of magnesium aluminometasilicate and is widely accepted as a multifunctional excipient that improves the quality of pharmaceuticals. Due to its large surface area and porous nature, Neusilin US2 adsorbs high loads of oils or water and can be mechanically compacted into high-quality tablets. It exhibits high adsorbing capacity and can be used to convert SMEDDS to S-SMEDDS [6-9]

Diacerein (DCN) is 4,5-diacetoxy-9,10-dioxo-9,10-dihydroanthracene2-carboxylic acid (Fig. 1) and mainly used for the treatment of osteoarthritis [10]. It is metabolized to active constituent rhein. Rhein is thought to act through inhibition of interleukin- $1 \beta$ and proteolytic enzymes along with which it stimulates the synthesis of cartilage components and modifies the understanding of pathological conditions [11]. As it does not inhibit the synthesis of prostaglandins, it is emerging, better and safe therapeutic agent as compared to NSAIDs [12]. It is used in treating rheumatoid arthritis and osteoarthritis. DCN aqueous solubility is $7-10 \mu \mathrm{g} / \mathrm{ml}$ at $\mathrm{pH} 7.0$ and at $40^{\circ} \mathrm{C}$. After oral administration, the peak plasma concentration is reported $2.2 \mathrm{~h}$ with even distribution in vivo and volume of distribution of 13.2 L in humans [13]. The poor solubility and wettability of DCN give rise to difficulties in pharmaceutical formulation meant for oral administration, which may lead to variation in bioavailability [14]. The present study was aimed to develop S-SMEDDS of DCN for enhanced solubility and dissolution rate.

\section{MATERIALS AND METHODS}

\section{Materials}

DCN was obtained as a gift sample from Virdev Intermediates Pvt., Ltd., Palsana, Surat, India. Neusilin US2 was gifted by Fuji Chemicals, Japan. Oleic acid was obtained from Loba Chemie Pvt., Ltd., Mumbai. Tween 80 and polyethylene glycol 200 (PEG 200) were obtained from S. D. Fine Chem., Mumbai. All other chemicals were of reagent grade.

\section{Methods}

Construction of pseudoternary phase diagram

From previous solubility, the study of DCN, oleic acid, Tween 80, and PEG 200 was selected as oil, surfactant, and cosurfactant, respectively. Hence, as to get stable SMEDDS, microemulsion region was identified by constructing pseudoternary phase diagram containing a different proportion of surfactant:cosurfactant $(\mathrm{km}=1: 1,2: 1$, and 3:1), oil and 


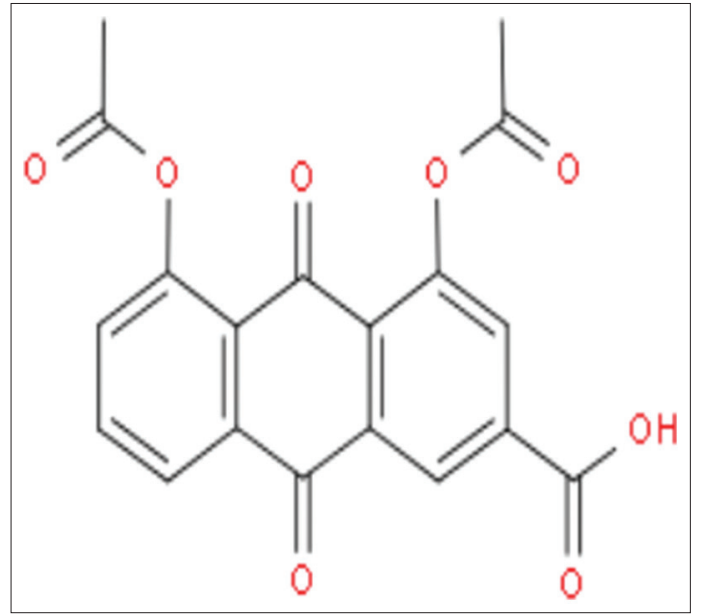

Fig. 1: Chemical structure of diacerein

water. In brief, $\mathrm{S}_{\text {mix }}$ and oil were mixed at a ratio of $1: 9,2: 8,3: 7,4: 6$, $5: 5,6: 4,7: 3,8: 2$, and $9: 1$ in a preweighed test tube. To the resultant mixtures, double distilled water was added dropwise until the first sign of turbidity observed, to identify the endpoint. After equilibrium, if the system became clear, then the water addition was continued $[6,15]$.

\section{Preparation of liquid SMEDDS}

Pseudoternary phase diagram of $\mathrm{km}=3$ was selected for the formulation of liquid SMEDDS as it showed high microemulsion region as compared to $\mathrm{km}=1$ and 2. From microemulsion region, three formulation batches DCN-L1, DCN-L2, and DCN-L3 were selected. The composition of different batches of liquid SMEDDS is shown in Table 1. In brief, DCN $(500 \mathrm{mg} / 10 \mathrm{~g})$ was placed in a glass vial. To this, oleic acid was added and warmed on a water bath. In this oily mixture, Tween 80 and PEG 200 in the proportion of 3:1 were added. Then, the components were mixed by gentle stirring and vortex mixing at $37^{\circ} \mathrm{C}$ until DCN was completely dissolved. Then, the mixture was sealed in a glass vial and stored at room temperature until used $[6,16]$.

\section{Evaluation of liquid SMEDDS $[3,6,17,18]$}

Thermodynamic stability studies

Thermodynamic stability study of prepared liquid SMEDDS was determined by carrying a heating-cooling cycle, centrifugation test, and freeze-thaw cycle.

\section{Robustness to dilution}

Robustness to dilution was studied by diluting liquid SMEDDS to 50, 100 , and 1000 times with water and $0.1 \mathrm{~N} \mathrm{HCl}$. The diluted SMEDDSs were stored for $12 \mathrm{~h}$ and observed for any signs of phase separation or drug precipitation.

\section{Assessment of the efficiency of self-emulsification}

The efficiency of self-emulsification was assessed by the procedure used by Khoo et al. using the United States Pharmacopeia (USP) - Type-II dissolution test apparatus (Veego VDA-8DR). $1 \mathrm{~mL}$ of liquid SMEDDS was added dropwise to $200 \mathrm{ml}$ of $0.1 \mathrm{~N} \mathrm{HCl}$ at $37^{\circ} \mathrm{C}$. Gentle agitation was provided by a standard stainless steel dissolution paddle rotating at $60 \mathrm{rpm}$. SMEDDS assessed visually according to the rate of emulsification and the final appearance of the emulsion [18].

\section{Percentage transmittance}

About $1 \mathrm{~mL}$ of liquid SMEDDS was diluted to $100 \mathrm{~mL}$ distilled water and observed for any turbidity and percentage transmittance was measured at $650 \mathrm{~nm}$ using ultraviolet (UV)-visible spectrophotometer (Shimadzu-1800, Japan) against distilled water as a blank [19].
Table 1: Composition of DCN liquid SMEDDS

\begin{tabular}{lllllll}
\hline Formulation & $\begin{array}{l}\text { DCN } \\
(\mathbf{m g} / \mathbf{1 0} \text { g) }\end{array}$ & \multicolumn{6}{l}{ \% composition $(\mathbf{w} / \mathbf{w})$} \\
\cline { 3 - 7 } & & $\begin{array}{l}\text { Oleic } \\
\text { acid }\end{array}$ & $\begin{array}{l}\text { Tween } \\
\mathbf{8 0}\end{array}$ & $\begin{array}{l}\text { PEG } \\
\text { 200 }\end{array}$ & $\mathbf{S}_{\text {mix }}$ & Water \\
\hline DCN-L1 & 500 & 10 & 30 & 10 & 40 & 50 \\
DCN-L2 & 500 & 10 & 37.5 & 12.5 & 50 & 40 \\
DCN-L3 & 500 & 10 & 45 & 15 & 60 & 30 \\
\hline
\end{tabular}

DCN: Diacerein, SMEDDS: Self-microemulsifying drug delivery system,

PEG 200: Polyethylene glycol 200

\section{Globule size, zeta potential, and viscosity}

Liquid SMEDDS was diluted to 10 times with distilled water and globule size and zeta potential were determined using Malvern Zetasizer. The viscosity of the all formulations was determined as such without dilution using Brookfield LVDV II + Pro viscometer using spindle S18 at $20 \mathrm{rpm}$ at room temperature.

\section{Dye solubilization test}

Hence, as to confirm the oil in water nature of SMEDDS a water-soluble dye eosin was sprinkled onto the surface of the prepared microemulsion and observed for spontaneous dispersion.

\section{Cloud point measurement}

Liquid SMEDDS was diluted with distilled water in the ratio of 1:250, placed in a water bath and its temperature was increased gradually. Cloud point was measured as the temperature at which there was a sudden appearance of cloudiness visually.

\section{Formulation of S-SMEDDS}

All three batches of liquid SMEDDS (DCN-L1, DCN-L2, and DCN-L3) were converted to S-SMEDDS (DCN-S1, DCN-S2, and DCN-S3) by adsorption technique using Neusilin US2. S-SMEDDS was prepared by mixing liquid SMEDDS containing DCN with Neusilin US2 in 1:1 proportion. In brief, liquid SMEDDS was added dropwise over Neusilin US2 contained in a broad porcelain dish. After each addition, the mixture was homogenized using a glass rod to ensure uniform distribution of formulation $[3,6]$.

\section{Evaluation of S-SMEDDS}

Micromeritic properties of S-SMEDDS

Prepared S-SMEDDS was evaluated for micromeritic properties such as angle of repose, bulk and tapped density, compressibility index, and Hausner ratio [18].

\section{Determination of drug content}

Drug content was calculated by dissolving S-SMEDDS equivalent to $500 \mathrm{mg}$ of DCN into $50 \mathrm{ml}$ measuring cylinder containing phosphate buffer of pH 6.8 with $0.03 \%$ of SLS and then sonicated for $15 \mathrm{~min}$ followed by filtered through the Whatman filter paper. It was then diluted suitably with phosphate buffer $\mathrm{pH} 6.8$ with $0.03 \%$ SLS. The absorbance of both standard and sample preparation after appropriate dilution was measured in UV spectrophotometer (Shimadzu-1800, Japan) at $258 \mathrm{~nm}$ using phosphate buffer pH 6.8 with $0.03 \%$ SLS [20].

\section{Reconstitution properties of S-SMEDDS}

Percentage transmittance, globule size, and zeta potential

Reconstituted S-SMEDDSs were also characterized for percentage transmittance, globule size, and zeta potential as described for liquid SMEDDS.

\section{In vitro dissolution study}

The dissolution study of different SMEDDS formulations and plain DCN was determined using a USP - Type I (basket type) apparatus under sink condition. The solid SMEDDSs containing $500 \mathrm{mg}$ of DCN were filled 
into hard gelatin capsules (capsule no. 00). The dissolution medium was $900 \mathrm{ml}$ phosphate buffer $\mathrm{pH} 6.8$ with $0.03 \%$ SLS at $37 \pm 0.5^{\circ} \mathrm{C}$ at $50 \mathrm{rpm}$, to simulate in vivo conditions. Dissolution study was carried out for $1 \mathrm{~h}$. A sample of $5 \mathrm{ml}$ was withdrawn at a predetermined time interval of 5 , $10,15,20,30,40,50$, and $60 \mathrm{~min}$ and filtered through Whatman filter paper and replaced by an equal volume of dissolution medium. The sample was suitably diluted with phosphate buffer $\mathrm{pH} 6.8$ with $0.03 \%$ SLS, and drug content in the dissolution sample was determined by UV spectrophotometer at $258 \mathrm{~nm}$ [21].

\section{Fourier transform infrared (FTIR) study of S-SMEDDS}

FTIR spectrum was recorded for DCN, a physical mixture of DCN:Neusilin US2 and prepared S-SMEDDS using Agilent Cary 630 FTIR spectrometer.

\section{Scanning electron microscopy (SEM)}

SEMs for prepared S-SMEDDS were taken using an SEM (JEOL, Japan) at accelerating voltage at $3-5 \mathrm{kV}$ to study surface topography.

\section{RESULTS AND DISCUSSION}

Identification of the microemulsion region by constructing a pseudoternary phase diagram

Constructed pseudoternary phase diagrams are shown in Fig. 2a-c. Phase behavior examination of this system established an appropriate approach to determine the concentration of oil, surfactant:cosurfactant and water so that transparent, monophasic low viscous microemulsion can be formed. Phase diagram of $\mathrm{km}=3$ showed maximum microemulsion region. Hence, it was selected for the development of liquid SMEDDS of DCN. Three points on microemulsion region were selected for the formulation of three batches of liquid SMEDDS (Fig. 2c). The selected composition of liquid SMEDDS is shown in Table 1.

\section{Evaluation of liquid SMEDDS}

\section{Thermodynamic stability studies}

The results of thermodynamic stability study showed that all formulations passed heating-cooling cycle test, hence, further exposed to centrifugation test. SMEDDS did not show any phase separation after centrifugation test, hence, was taken for a freeze-thaw stress test. After the freeze-thaw stress test, it was found that SMEDDS showed good stability without phase separation.

\section{Robustness to dilution}

Results showed that no any sign of phase separation and precipitation after dilution of formulations with water and $0.1 \mathrm{~N} \mathrm{HCl}$.

\section{Assessment of Efficiency of self-emulsification}

All three formulations of liquid SMEDDS rapidly formed clear and slightly bluish microemulsion within 1 min. Hence, as per the grading system explained by Khoo et al. [17], all formulations were passed this test as per Grade A.

Percentage transmittance, globule size, zeta potential, and viscosity

Percentage transmittance of reconstituted liquid SMEDDS of all batches was found to be in between $89.4 \pm 0.52$ and $92.30 \pm 0.64$. Globule size was found to be between 0.189 and $0.246 \mu \mathrm{m}$. Zeta potential of liquid SMEDDS was found to be $-6.8--9.7 \mathrm{mV}$. The viscosity of all formulations was found to be in between $20.14 \pm 1.2$ and $26.32 \pm 0.98$ cps.

\section{Dye solubilization test and cloud point measurement}

Dye solubilization test showed that rapid incorporation of the watersoluble dye (eosin) into the system which indicates that the continuous phase was water; hence, the type of microemulsion formed was found

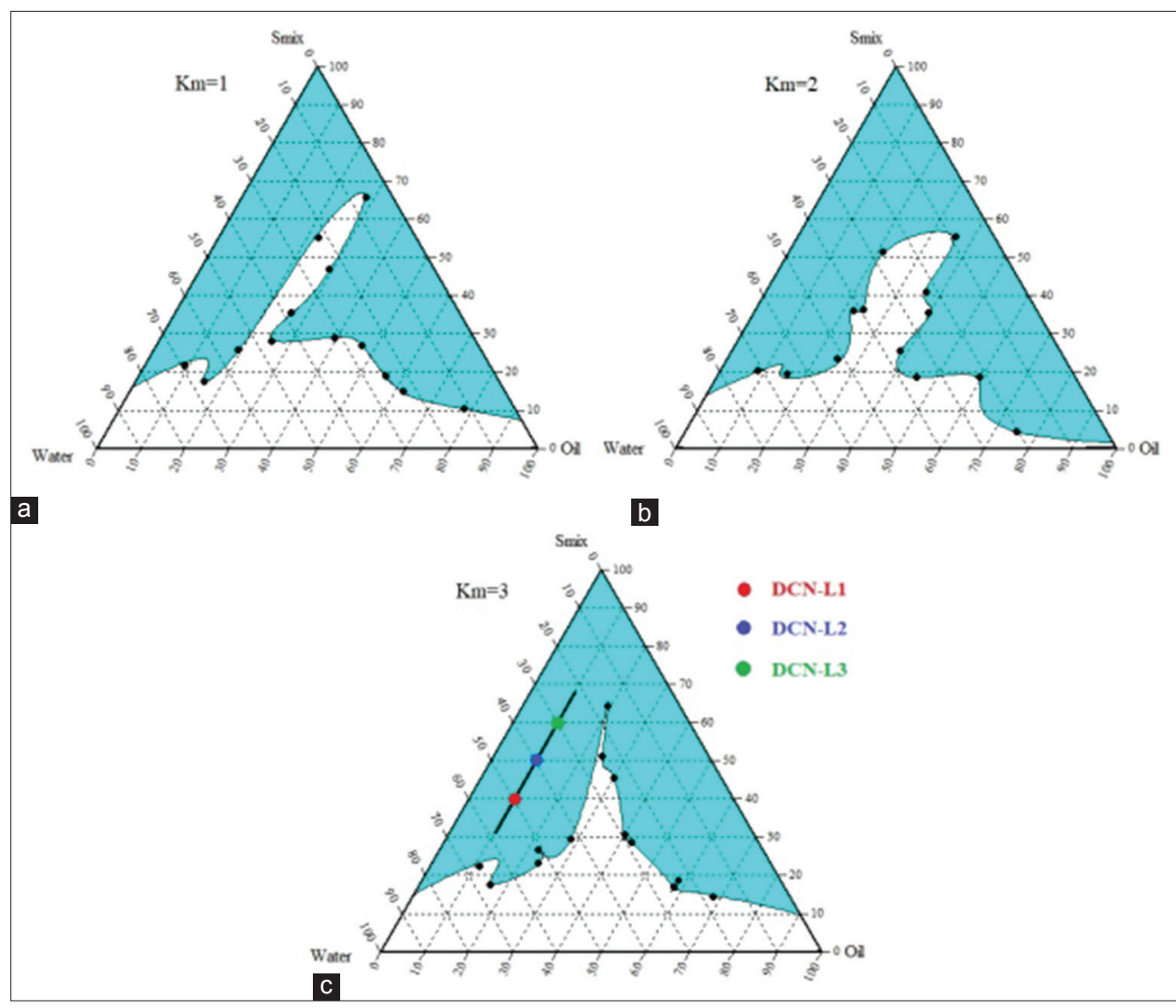

Fig. 2: Pseudoternary phase diagram at different $\mathrm{km}$ value: (a) $\mathrm{km}=1: 1$, (b) $\mathrm{km}=2: 1$ and (c) $\mathrm{km}=3: 1$ 
Table 2: Micromeritic properties and drug content of DCN S-SMEDDS

\begin{tabular}{llllll}
\hline Formulation & $\begin{array}{l}\text { Angle of } \\
\text { repose }\end{array}$ & $\begin{array}{l}\text { Bulk density } \\
\text { (g/mL) }\end{array}$ & $\begin{array}{l}\text { Tapped density } \\
\text { (g/mL) }\end{array}$ & $\begin{array}{l}\text { Compressibility } \\
\text { index (\%) }\end{array}$ & $\begin{array}{l}\text { Hausner's } \\
\text { ratio }\end{array}$ \\
\hline DCN-S1 & $20.02 \pm 1.25$ & $0.520 \pm 0.03$ & $0.598 \pm 0.03$ & $13.04 \pm 0.04$ & $1.15 \pm 0.04$ \\
DCN-S2 & $19.52 \pm 2.32$ & $0.517 \pm 0.04$ & $0.646 \pm 0.03$ & $15.52 \pm 0.04$ & $95.28 \pm 2.85$ \\
DCN-S3 & $18.86 \pm 1.08$ & $0.642 \pm 0.02$ & $0.723 \pm 0.04$ & $11.20 \pm 0.02$ & $98.67 \pm 1.89$ \\
\hline
\end{tabular}

DCN: Diacerein, S-SMEDDS: Solid self-microemulsifying drug delivery system

Table 3: Percentage transmittance, globule size, and zeta potential of S-SMEDDS

\begin{tabular}{llll}
\hline Formulation & \% transmittance & $\begin{array}{l}\text { Globule } \\
\text { size }(\boldsymbol{\mu m})\end{array}$ & $\begin{array}{l}\text { Zeta } \\
\text { potential }(\mathbf{m V})\end{array}$ \\
\hline DCN-S1 & $92.32 \pm 2.78$ & 0.276 & -7.12 \\
DCN-S2 & $94.76 \pm 3.12$ & 0.277 & -8.56 \\
DCN-S3 & $95.45 \pm 1.82$ & 0.271 & -16.18 \\
\hline
\end{tabular}

DCN: Diacerein, S-SMEDDS: Solid self-microemulsifying drug delivery system

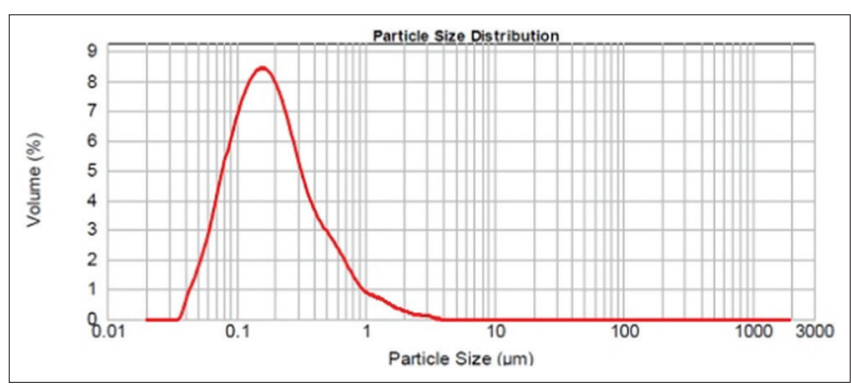

Fig. 3: Globule size of reconstituted solid self-microemulsifying drug delivery system of batch diacerein-S3

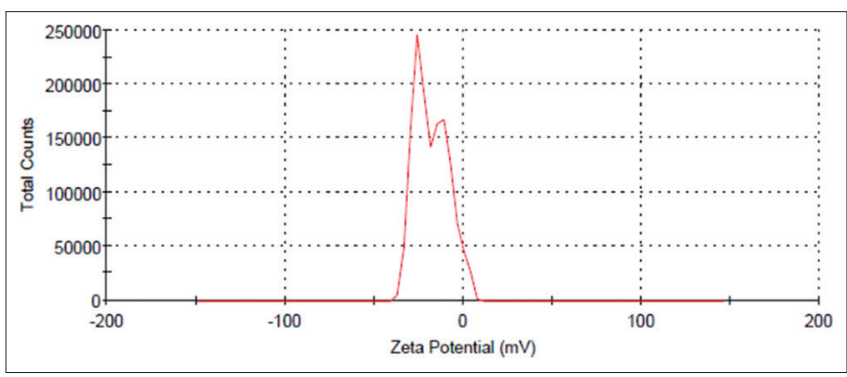

Fig. 4: Zeta potential of reconstituted solid self-microemulsifying drug delivery system of batch diacerein-S3

to be of o/w type. The cloud point of prepared liquid SMEDDS was found to be $>80^{\circ} \mathrm{C}$ for all formulations, which indicate that microemulsion will be stable at physiological temperature without risk of phase separation.

\section{Micromeritic properties and drug content of S-SMEDDS}

Micromeritic properties such as angle of repose, bulk and tapped density, compressibility index, and Hausner ratio and drug content of S-SMEDDS are shown in Table 2. Results showed that prepared S-SMEDDS shows good flow properties and drug content.

\section{Reconstitution properties of S-SMEDDS}

Percentage transmittance, globule size, and zeta potential

The results of percentage transmittance, globule size, and zeta potential are summarized in Table 3. The results of percentage transmittance indicate that reconstituted S-SMEDDS of DCN was found to be clear. Globule size and zeta potential of batch DCN-S3 are shown in Figs. 3 and 4 , respectively.

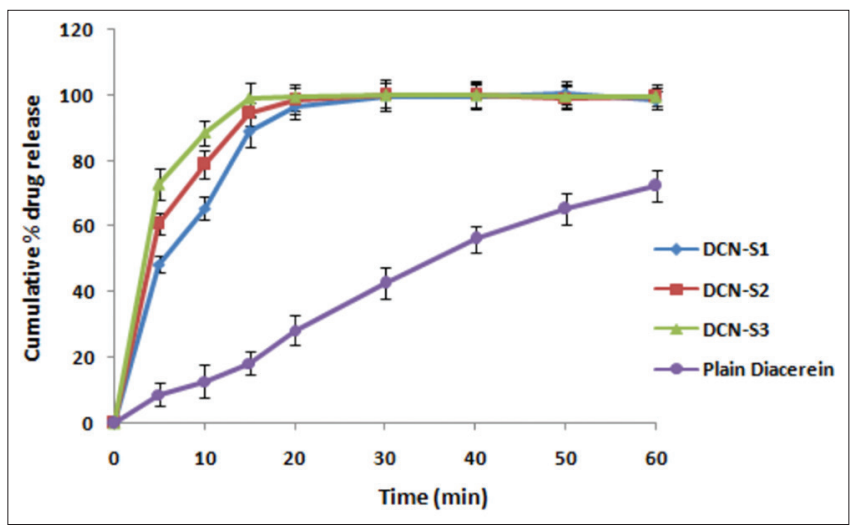

Fig. 5: Cumulative percentage drug release of solid selfmicroemulsifying drug delivery system and plain diacerein

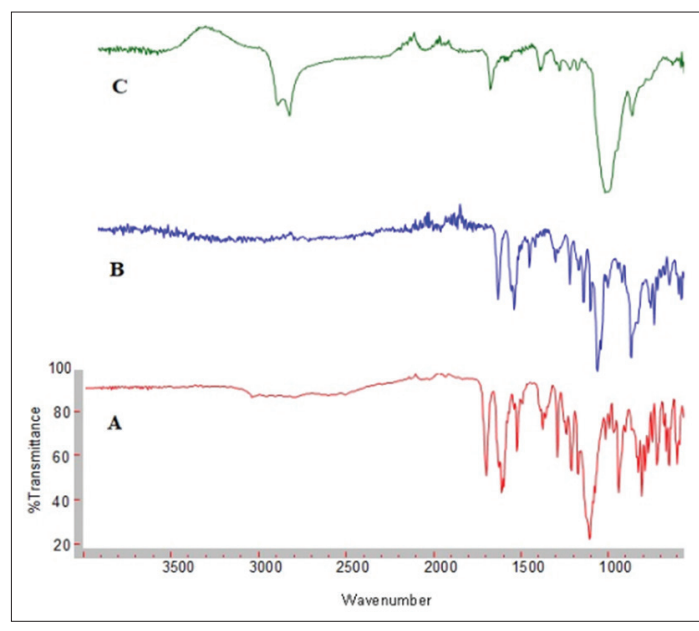

Fig. 6: Fourier transform infrared spectra of A: Plain diacerein (DCN), B: DCN:Neusilin US2 physical mixture, C: S-SMEDDS
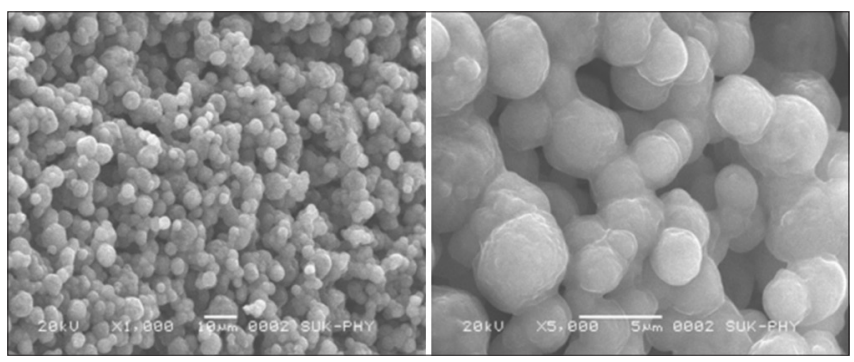

Fig. 7: Scanning electron microscopy of solid selfmicroemulsifying drug delivery system of batch diacerein-S3

In vitro dissolution study

Cumulative percentage drug release of all batches of the DCN S-SMEDDS and plain DCN in phosphate buffer pH 6.8 with $0.03 \%$ SLS is shown in Fig. 5. S-SMEDDS formulations showed that $>95 \%$ of drug release within 20 min. While plain DCN shows $28.45 \%$ drug release after 
$20 \mathrm{~min}$. It indicates that drug releases from S-SMEDDS were found to be significantly higher as compared to plain DCN.

\section{FTIR study of S-SMEDDS}

FTIR spectrum of DCN, DCN:Neusilin US2 physical mixer, and S-SMEDDS of batch DCN-S3 is shown in Fig. 6. Deformation of characteristic peaks of DCN in S-SMEDDS may be due to the formation of the amorphous state of DCN.

\section{SEM}

Fig. 7 shows SEM of S-SMEDDS formulation of batch DCN-S3. This shows that S-SMEDDS appeared as smooth-surfaced particles, indicating liquid SMEDDS is adsorbed or coated inside the pores of Neusilin US2.

\section{CONCLUSION}

The study concluded that prepared liquid SMEDDS was thermodynamically stable with good self-emulsification efficiency and having globule size in the micrometer range. Liquid SMEDDS can effectively be converted into S-SMEDDS by adsorption technique using Neusilin US2 as a solid carrier. From reconstitution properties of S-SMEDDS, it can be said that there is no effect on self-emulsification ability and globule size after conversion of liquid SMEDDS into solid. FTIR study showed that there is no significant interaction between DCN and Neusilin US2. SEM showed that spherical S-SMEDDS can be obtained which can be filled into a capsule or compressed in to tablet. Cumulative percentage drug release was found to be much higher than that of plain DCN. It may be due to an increase in solubility of the drug. Hence, the study concluded that solubility, dissolution, and, hence, bioavailability of poorly water-soluble drug like DCN can be increased by formulating S-SMEDDS.

\section{ACKNOWLEDGMENT}

The authors are thankful to the Management and Principal of Rajarambapu College of Pharmacy, Kasegaon, for constant inspiration and making necessary facilities available for the work and Fuji Chemicals, Japan, for providing gift sample of Neusilin US2.

\section{AUTHORS' CONTRIBUTIONS}

Tamboli JA conceived, designed and performed the experiments, and analyzed the data. Dr. Mohite SK guided the entire formulation and principle of the research work. Both were involved in writing the paper.

\section{CONFLICTS OF INTEREST}

The authors declare that they have no conflicts of interest.

\section{REFERENCES}

1. Jain KK. Drug Delivery Systems-An Overview. Totowa, New Jersey: Humana Press; 2008. p. 2.
2. Hauss DJ. Oral lipid-based formulations. Adv Drug Deliv Rev 2007; 59:667-76.

3. Bhagwat DA, D'Souza JI. Formulation, and evaluation of solid selfmicro emulsifying drug delivery system using aerosil 200 as a solid carrier. Int Curr Pharm J 2012;1:414-9.

4. Kohli K, Chopra S, Dhar D, Arora S, Khar RK. Self-emulsifying drug delivery systems: An approach to enhance oral bioavailability. Drug Discov Today 2010;15:958-65.

5. Shah SP, Shah MD, Agrawal YK. Self-micro emulsifying drug delivery system: A novel approach for enhancement of oral bioavailability of poorly soluble drugs. Am J PharmTech Res 2012;2:193-215.

6. Bhagwat DA, D'Souza JI. Development of solid self-micro emulsifying drug delivery system with neusilin US2 for enhanced dissolution rate of telmisartan. Int J Drug Dev Res 2012;4:398-407.

7. Agarwal V, Siddiqui A, Ali H, Nazzal S. Dissolution and powder flow characterization of solid self-emulsified drug delivery system (SEDDS). Int J Pharm 2009;366:44-52.

8. Raval C, Joshi N, Patel J, Upadhyay UM. Enhanced oral bioavailability of olmesartan by using novel solid self-emulsifying drug delivery system. Int J Adv Pharm 2012;2:82-92.

9. Shaji J, Jadhav D. Newer approches to self-emulsifying drug delivery system. Int J Pharm Pharm Sci 2010;2 Suppl 1:37-42.

10. Yadav DS, Yadav AA, Karekar PS, Pore YV, Gajare PS. Preparation and characterization of diacerein microcrystals. Pharm Lett 2012;4:428-35.

11. Fidelix TS, Macedo CR, Maxwell LJ, Fernandes Moça Trevisani V. Diacerein for osteoarthritis. Cochrane Database Syst Rev 2014; 2:CD005117.

12. Khyati KP, Jalpa SP, Moinnudin MS. Formulation and evaluation of nanosuspension to improve solubility and dissolution of diacerein. Int $\mathrm{J}$ Pharm Sci Res 2017;8:1643-53.

13. Walke PS, Khairnar PS, Narkhede MR, Nehete JY. Solubility enhancement of diacerein by mannitol solid dispersions. Int J Pharm Pharm Sci 2011;3:261-4.

14. Deshmukh DB, Gaikwad PD, Bankar VH, Pawar SP. Dissolution enhancement of poorly water soluble diacerein by solid dispersion technique. J Pharm Sci Res 2010;2:734-9.

15. Jha SK, Dey S, Kark R. Micro emulsions-potential carrier for improved drug delivery. Int Pharm Sci 2011;1:25-31.

16. Kang BK, Lee JS, Chon SK, Jeong SY, Yuk SH, Khang G, et al. Development of self-microemulsifying drug delivery systems (SMEDDS) for oral bioavailability enhancement of simvastatin in beagle dogs. Int J Pharm 2004;274:65-73.

17. Date AA, Nagarsenker MS. Design and evaluation of self-nano emulsifying drug delivery systems (SNEDDS) for cefpodoxime proxetil. Int J Pharm 2007;329:166-72.

18. Khoo SM, Humberstone AJ, Porter CJ, Edwards GA, Charman WN. Formulation design and bioavailability assessment of lipidic selfemulsifying formulations of halofantrine. Int J Pharm 1998;167:155-64.

19. More HN, Hajare AA. Practical Physical Pharmacy. $2^{\text {nd }}$ ed. Nashik: Career Prakashan; 2010. p. 129-31.

20. Shukla JB, Jani GK, Omri AW. Formulation and evaluation of oral self microemulsifying drug delivery system of candesartan cilexetil. Int $\mathbf{J}$ Pharm Pharm Sci 2016;8:238-43.

21. Padmapreetha J, Arulkumaran KS. Improvement of dissolution rate of diacerein using liquisolid technique. J Chem Pharm Res 2016;8:209-19. 